\title{
IMPROVEMENTS OF TRUCK FUEL ECONOMY USING MECHANICAL REGENERATIVE BRAKING
}

\author{
Alberto A. Boretti \\ School of Science and Engineering, University of Ballarat, Victoria, Australia
}

Copyright (C) 2010 SAE International

\begin{abstract}
Improvements of truck fuel economy are being considered using a flywheel energy storage system concept. This system reduces the amount of mechanical energy needed by the thermal engine by recovering the vehicle kinetic energy during braking and then assisting torque requirements. The mechanical system has an overall efficiency over a full regenerative cycle of about $70 \%$, about twice the efficiency of battery-based hybrids rated at about $36 \%$. The technology may improve the vehicle fuel economy and hence reduced $\mathrm{CO}_{2}$ emissions by more than $30 \%$ over driving cycles characterized by: frequent engine start/stop, vehicle acceleration, brief cruising, deceleration and stop. The paper uses engine and vehicle simulations to compute: first the fuel benefits of the technology applied to passenger cars, then the extension of the technology to deal with heavy duty vehicles.
\end{abstract}

\section{INTRODUCTION}

Developing more energy-efficient and environmentally friendly highway transportation technologies based on heavy duty gas engines is a key factor for reducing fuel consumption, $\mathrm{CO}_{2}$ production and pollutants emissions within Australia therefore improving national energy security, environment, and economy.

Up until the early 1960 s, railways dominated all but the shortest land-based freight task. Since then, vast improvements in road vehicle productivity, road infrastructure quality, the gradual removal of regulations restricting road freight carriage and the exponential growth in interstate trade has broadened the range of freight tasks for which road is better suited than rail. The Australian domestic freight task measured 521 billion tons kilometers in 2007, with $35 \%$ carried by road [1], having road trains covering the most part of interstate traffic.

Australia has the largest and heaviest road vehicles in the world, with some configurations topping out at close to 200 tones. Twotrailer road trains, or B-doubles, are allowed in most parts of Australia, with the exception of some urban areas. Three trailer road trains or B-triples operate in western New South Wales, western Queensland, South Australia, Western Australia and the Northern Territory, with the last three states also allowing AB-Quads (3.5 trailers). Road trains are used for transporting all manner of materials. Their cost-effective transport has played a significant part in the economic development of remote areas, with some communities totally reliant on a regular service.

The domestic freight task has doubled in size over the past 20 years, with an averaging growth of 3.5\% per annum. BITRE (the Australian government Bureau of Infrastructure, Transport and Regional Economics) projections [1] suggest this trend will continue, although with slightly slower growth into the future, growing by approximately $3.0 \%$ per annum until 2030 . Over this period, road freight volumes are projected to more than double, with domestic demand for manufactured goods sustaining much of the growth, even if .the global financial crisis will certainly dampen freight growth in the near term. Australia's annual green house gases emissions through to the 2009 June quarter for energy - transport amount to $89 \mathrm{Mt} \mathrm{CO}_{2}$-e [2], or about the $14.5 \%$ of the total.

Improving the efficiency of internal combustion engines is the most promising and cost-effective approach to increasing vehicle fuel economy in the next 10 to 20 years, or until such time still far to forecast when plug-in hybrid electric or fuel cell hybrid vehicles will dominate the market [3]. Advanced combustion engines still have great potential for achieving dramatic energy efficiency improvements in heavy-duty vehicle applications. The primary hurdles that must be overcome to realize increased use of advanced combustion engines are: the higher cost of these engines which still require expensive R\&D when compared to conventional engines and compliance with particularly stringent new emission regulations. The catalytic emission control technologies for lean burn advanced combustion engines are indeed much less mature than the stoichiometric gasoline engine catalysts, and they also require costly R\&D. 
In addition to advanced combustion engines and alternative fuels, the author is also considering the possible Improvements of truck fuel economy using a flywheel energy storage system. The concept would reduce the amount of mechanical energy produced by the thermal engine by recovering the vehicle kinetic energy during braking and then assisting with torque requirements. The mechanical system has an overall efficiency over a full regenerative cycle of about $70 \%$, about twice the efficiency of battery-based hybrids rated at about 36\%. The technology may improve the vehicle fuel economy and hence reduce $\mathrm{CO}_{2}$ emissions by more than $30 \%$ over driving cycles characterized by frequent engine start/stop, vehicle acceleration, brief cruising, deceleration and stop. This technology is now being developed for passenger car applications, with the extension to commercial vehicles introducing further challenges and opportunities.

Hydraulic Regenerative Braking (HRB) has already been proposed for Heavy Duty Trucks [4] to recover the braking energy with a high efficiency on a regenerative loop. When the driver steps on the brake, the vehicle's kinetic energy powers a reversible pump, which sends hydraulic fluid from a low pressure reservoir inside the vehicle into a high pressure accumulator. The pressure is created by compressing nitrogen gas in the accumulator as the fluid is pumped in to displace the nitrogen. This slows the vehicle and helps bringing it to a stop.

The fluid remains under pressure in the accumulator until the driver pushes the accelerator again. Then the pump reverses and the pressurized fluid is used to accelerate the vehicle, effectively translating the kinetic energy that the truck had before braking into mechanical energy that helps to speed up the vehicle again. It is predicted [4] that a system like this could store $80 \%$ of the momentum lost by a vehicle during deceleration and use it to get the vehicle moving again. Actual regenerative cycle efficiencies are probably smaller than that.

So far, HRB systems have been used primarily as proofs of concept and in demonstration projects only. They are not ready for production models. These hydraulic brakes are noisy and prone to leaks and the accumulators take up a considerable amount of space. Once all of these issues are solved, such systems will probably be most useful in large trucks weighing 4,500 kilograms or more, where hydraulic brakes may prove to be a more optimal system than much less efficient electronically controlled regenerative brakes. Flywheel based kinetic energy recovery systems (KERS) may offer many advantages compared to HRB providing about the same efficiency on a braking cycle with reduced complexity and less space needed.

Passenger car applications are now covered by KERS. Truck applications would need larger capacity flywheel storage devices, but the fuel savings would be higher due to the heavy use of fuel in truck based transport. More expensive systems would be financially viable. Furthermore, there would be great benefits in providing the energy boost to help trucks climbing hills. As well as fuel savings we expect road safety could be improved as the current energy deficiency in climbing hills may lead to many frustrated motorist taking risks to overtake them. KERS will also collect considerable energy braking down hills not just in reducing speed but also in maintaining a safe speed. KERS may also reduce the need for engine brakes and thus noise. For truck application, it could be cost effective to include magnetic bearings and drives. The increased mass of the flywheel may be possibly detrimental to stability although the increase in vehicle mass could possibly balance this effect. Two counter rotating flywheels could eliminate losing stability.

The paper uses engine and vehicle simulations to compute first the fuel benefits of the technology applied to passenger cars, and then extends the technology to deal with heavy duty vehicles. Engine simulations are performed by using the wave code [17]. Vehicle simulations are performed by using the lotus vehicle code [18]. Wave is one of the market-leading $1 \mathrm{~d}$ engine \& gas dynamics simulation software package. It is widely used in the automotive industry. Over the last two decades, wave has been the subject of a large number of conference papers and journal articles. Lotus vehicle simulation is map look-up based software able to accurately predict performance, emissions, fuel consumption and lap time of a modeled vehicle. Lotus vehicle simulation is also a very well established procedure.

\section{KERS FUNDAMENTALS}

It is one of the fundamentals of physics that transforming energy from one form to another inevitably introduces significant losses. This explains why the efficiency of battery-based hybrids is so low for a regenerative braking cycle. When a battery is involved, there are four efficiency reducing transformations in each regenerative braking cycle. Kinetic energy is transformed into electrical energy in a motor/generator, the electrical energy is transformed into chemical energy as the battery charges up, the battery discharges transforming chemical into electrical energy, the electrical energy passes into the motor/generator acting as a motor and is transformed once more into kinetic energy. The four energy transformations reduce the overall level of efficiency. If the motor/generator operates at $80 \%$ efficiency under peak load, in and out, and the battery charges and discharges at $75 \%$ efficiency at high power, the overall efficiency over a full regenerative cycle is only $36 \%$.

The ideal solution is to avoid all four of the efficiency reducing transformations from one form of energy to another by keeping the vehicle's energy in the same form from when the vehicle starts braking to when the vehicle is back up to speed. This can be done using high-speed flywheels, popular in space and uninterruptible power supplies for computer systems, but novel in ground vehicles. For the space and computer applications, high-speed motor/generators are used to add and remove energy from the flywheels. In ground vehicles, more efficient mechanical, geared systems are preferred. A mechanically driven flywheel system has losses, due to friction in bearings and windage effects, which make it less efficient than a battery-based system in storing energy for long times. 
Over the much shorter periods required in cut-and-thrust traffic, a mechanically driven flywheel is much more effective, providing an overall efficiency over a full regenerative cycle of more than $70 \%$, almost twice the value of battery-based hybrids [9-15, 32,33].

Almost every vehicle with a manual transmission is already fitted with a flywheel to smooth the flow of power from the engine and to provide a small store of energy to help prevent stalling on launch. Toy cars use a small flywheel geared up to spin fast enough to provide spectacular scale performance. The geared high-speed flywheel concept is now applied to full-sized cars, trucks and buses. The result is a dramatic improvement in fuel economy, at lower cost, without sacrificing acceleration.

This paper aims to compute through vehicle simulations, the improvements in fuel efficiency over a driving cycle recovering the braking energy with a mechanically driven flywheel to stop the thermal engine at idle, during braking and during accelerations when energy is available in the flywheel therefore reducing the supply of fuel energy needed to power the vehicle. Fuel economy can be increased by reducing the amount of mechanical energy to be provided by the thermal engine by recovering the braking energy and shutting down the engine during decelerations, at rest and during the portion of the acceleration following a deceleration that can be covered by the energy stored.

Considering the theoretical advantages of storing braking mechanical energy with a much more efficient, simple and lighter mechanical device, and the recent improvements in kinetic energy recovery systems (KERS) for F1 applications [5 to 15]. Improvements in fuel economy are being considered using a KERS to recover the braking energy and to buffer the thermal engine.

KERS stores energy under vehicle braking and returns it under vehicle acceleration. The system utilizes a flywheel as the energy storage device and a Continuously Variable Transmission (CVT) to transfer energy from and to the driveline. Transfer of vehicle kinetic energy to flywheel kinetic energy reduces the speed of the vehicle and increases the speed of the flywheel. Transfer of flywheel kinetic energy to vehicle kinetic energy reduces the speed of the flywheel and increases the speed of the vehicle. The CVT is used because ratios of vehicle and flywheel speed are different during a braking or acceleration event. A clutch allows disengagement of the flywheel when not used.

For a traditional power train, the driveline equation balances vehicle side output torque from clutch or torque converter with inertia torque of the entire driveline and vehicle and the effective torque of the retarding forces on the vehicle, namely aerodynamic, rolling resistance and grade forces:

$$
\begin{aligned}
& \tau_{d r v, v}=\left[I_{\text {trans } 1}+\frac{I_{\text {trans } 2}}{R_{t}^{2}}+\frac{I_{d s h}}{R_{t}^{2}}+\frac{I_{a x l}}{R_{d}^{2} R_{t}^{2}}+\frac{M_{v e h} r_{w h l}^{2}}{R_{d}^{2} R_{t}^{2}}\right] \frac{d \omega_{d r v}}{d t} \\
- & {\left[\frac{I_{\text {trans } 2}}{R_{t}^{3}}+\frac{I_{d s h}}{R_{t}^{3}}+\frac{I_{a x l}}{R_{d}^{2} R_{t}^{3}}+\frac{M_{v e h} r_{w h l}^{2}}{R_{d}^{2} R_{t}^{3}}\right] \omega_{d r v} \frac{d R_{t}}{d t} } \\
+ & {\left[\frac{F_{a e r}+F_{r o l}+F_{g r d}}{R_{d} R_{t}}\right] r_{w h l} }
\end{aligned}
$$

Where: $\tau_{d r v, e}$ is the engine side torque of clutch or torque converter, $\tau_{d r v, v}$ the vehicle side torque of clutch or torque converter. $\omega_{d r v}$ the driveline speed on vehicle side of clutch or torque converter, $\mathrm{I}_{a x l}$ the axle moment of inertia, $\mathbf{I}_{d s h}$ the driveshaft inertia, $\mathbf{I}_{t r a n s 1}$ the input side transmission moment of inertia, $\mathbf{I}_{\text {trans } 2}$ the output side transmission moment of inertia, $\mathbf{M}_{v e h}$ the vehicle mass, $\mathbf{r}_{w h l}$ the wheel radius, $\mathbf{F}_{a e r}$ the aerodynamic force on vehicle, $\mathbf{F}_{\text {rol }}$ the rolling resistance force on vehicle, $\mathbf{F}_{\text {grd }}$ the grade force on vehicle, $\mathbf{R}_{t}$ the transmission ratio, $\mathbf{R}_{\boldsymbol{d}}$ the final drive ratio, $\mathbf{t}$ the time. This equation and the engine equation of motion, this latter balancing engine brake torque with engine inertia torque and engine side load torque from the clutch or torque converter, determine the operating points (torque and speed) of the engine. Braking at the wheels may be assimilated to a torque component, or even better to a slipping clutch component. Either way, braking at the wheels dissipates the kinetic energy of the vehicle that is therefore lost.

The kinetic energy of the flywheel is $\mathbf{E}=1 / 2 \cdot \mathbf{J} \cdot \boldsymbol{\omega}^{2}$ where $\mathbf{J}$ is the moment of inertia of the flywheel and $\boldsymbol{\omega}$ the angular velocity. The flywheel has a moment of inertia $\mathbf{J}=\frac{1}{2} \cdot \mathbf{m} \cdot\left(\mathbf{r}_{1}{ }^{2}-\mathbf{r}_{2}{ }^{2}\right)$, where $\mathbf{m}$ is the mass, $\mathbf{r}_{1}$ the outer radius and $\mathbf{r}_{2}$ the inner radius. It is possible to use low speed high inertia flywheels, or high speed low inertia flywheels, to store same energy. F1 systems use a very light weight composite flywheel, made up of a carbon fiber filament wound rim surrounding a steel hub, rotating at very high speed in a vacuum [13-19]. This design has proved to be quite effective but also quite expensive to produce, with other solutions being considered for mass production [20].

The dynamic behavior of a rigid flywheel rotor in bearings on elastic supports (elastic to account for finite stiffness of bearings, shaft and structures), allows two modes of operation, sub-critical with flywheel speed ranging from zero to a speed that is safely below the first critical speed, and super-critical with flywheel speed ranging between two consecutive critical speeds [29]. The first mode of operation permits low energy storage, and only the second mode for high energy storage is considered. Wheel braking is therefore partially replaced by increasing the flywheel speed of rotation from a low to a high value, thus storing part of the available kinetic energy. This stored kinetic energy is then used to reaccelerate the vehicle reducing the flywheel speed of rotation from a high to a low value.

System efficiency is a key area where the mechanical hybrid system excels over the electric hybrid. Battery based electric hybrid systems require a number of energy conversions each with corresponding efficiency losses. On reapplication of the energy to the 
drive line, the global energy conversion efficiency is 31-34\% [12]. The mechanical hybrid system storing energy mechanically in a rotating fly wheel eliminates the various energy conversions and provides a global energy conversion efficiency exceeding $70 \%$, more than twice the efficiency of an electric system [9-15]. However, it is to be pointed out that KERS stores energy efficiently only during a small time interval. Therefore more complex buffering strategies where the thermal engine operation is virtually decoupled by the road load that are possible with electric hybrid vehicles are not possible with mechanical hybrid vehicles.

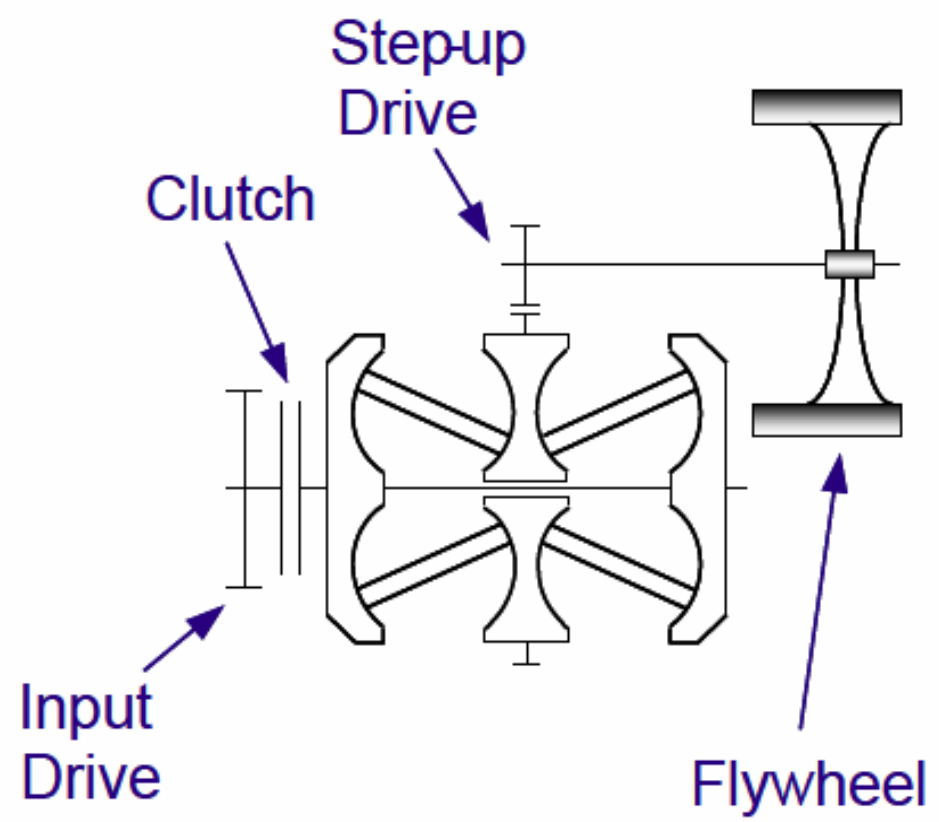

Figure 1 - Schematic flywheel mechanical hybrid system (from [11, 13, 14]).
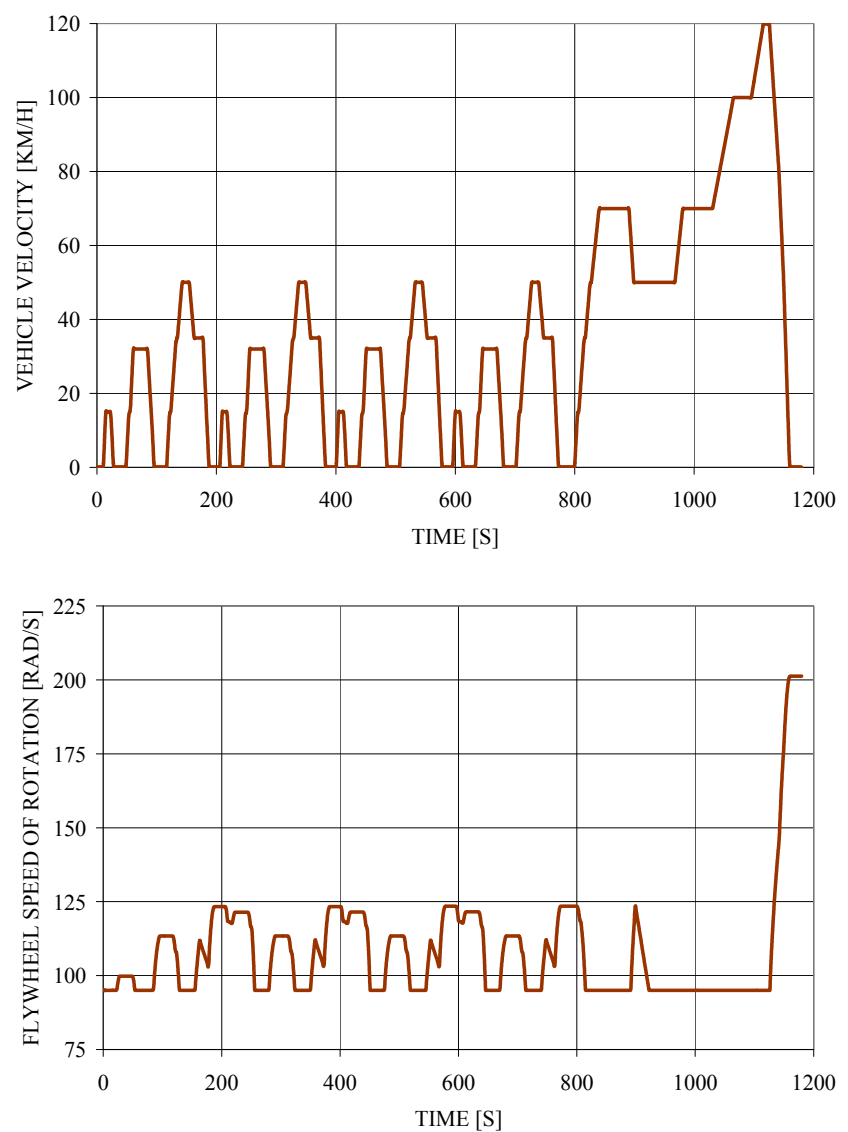

Figure 2 - Vehicle velocity and flywheel speed of rotation for a passenger car over the New European Driving Cycle. 
Recovery of the braking energy reduces the amount of thermal energy requested to power the vehicle and reduce the time the thermal engine is on. Efficiency of KERS energy storage and release, maximum amount of energy being stored, energy loss in start/stop of engine and timing of deceleration and acceleration processes and therefore efficiency of the control play a dominant role in determining the best configuration of a KERS assisted power train. Using optimized strategies $\mathrm{CO}_{2}$ and fuel consumption reductions of over 20\% are possible on the New European Driving Cycle (NEDC) and more than 30\% is possible in real world conditions [5].

Figure 1 describes a schematic flywheel mechanical hybrid system (from [11, 13, 14]). This figure explains the KERS storage of energy under vehicle braking and the KERS release of previously stored energy during the subsequent vehicle acceleration. The system utilizes a flywheel as the energy storage device and a Continuously Variable Transmission (CVT) to transfer energy to and from the driveline. Transfer of vehicle kinetic energy to flywheel kinetic energy reduces the speed of the vehicle and increases the speed of the flywheel. Transfer of flywheel kinetic energy to vehicle kinetic energy reduces the speed of the flywheel and increases the speed of the vehicle. The CVT is used because ratios of vehicle and flywheel speed are different during a braking or acceleration event. A clutch allows disengagement of the flywheel when not used.

Figure 2 shows vehicle and flywheel speed for a passenger car over the New European Driving Cycle. Every deceleration of the car produces an acceleration of the flywheel from a minimum speed of rotation to a larger speed of rotation following the transfer of energy from wheels to flywheel. The speed of rotation of the flywheel is then reduced back to the minimum speed as soon as the flywheel energy is transferred back to the wheels to power the vehicle for acceleration or cruise. The thermal engine is shut-off during braking and it is restarted when the energy stored in the flywheel is consumed.

\section{PASSENGER CAR CYCLES}

Fuel economy and emission compliance is measured over test cycles. The ECE+EUDC cycle is a test cycle performed on a chassis dynamometer used for emission certification of light duty vehicles in Europe (Economic Commission for Europe (ECE) Directive 90/C81/01, [30]). The entire cycle includes four ECE segments, repeated without interruption, followed by one Extra Urban Driving Cycle (EUDC) segment.

Before the test, the vehicle is allowed to soak for at least 6 hours at a test temperature of $20-30^{\circ} \mathrm{C}$. It is then started and the emission sampling begins at the same time. This cold-start procedure is also referred to as the New European Driving Cycle (NEDC). The ECE cycle is an urban driving cycle, also known as UDC. It was devised to represent city driving conditions, e.g. in Paris or Rome. It is characterized by low vehicle speed, low engine load, and low exhaust gas temperature. The EUDC (Extra Urban Driving Cycle) segment has been added after the fourth ECE cycle to account for more aggressive, high speed driving modes. The maximum speed of the EUDC cycle is $120 \mathrm{~km} / \mathrm{h}$. The prescribed velocity of the car is the one of Figure 2. Table 1 summarizes the parameters for both the ECE and EUDC cycles obtained analysing this velocity schedule.

\begin{tabular}{||c|c|c||}
\hline Characteristics & ECE & EUDC \\
\hline Distance $[\mathrm{km}]$ & $4 \times 1.013=4.052$ & 6.955 \\
\hline Duration $[\mathrm{s}]$ & $4 \times 195=780$ & 400 \\
\hline Average Speed $[\mathrm{km} / \mathrm{h}]$ & 18.7 (with idling) & 62.6 \\
\hline Maximum Speed $[\mathrm{km} / \mathrm{h}]$ & 50 & 120 \\
\hline
\end{tabular}

Table 1 - Main characteristics of ECE and EUDC sectors.

\section{FULL SIZE GASOLINE PASSENGER CAR}

Simulations have then been performed for a large full size passenger car. The car is powered by a naturally aspirated, 4 liters, stoichiometric gasoline engine. Basic data of the engine and the vehicle are presented in Tables 2 and 3 . Figure 3 presents the Brake Specific Fuel Consumption (BSFC) vs. Brake Mean Effective Pressure (BMEP) and engine speed. These values are computed with a validated engine model (WAVE, [17]).

Results of vehicle fuel economy over the NEDC have then been obtained with a validated vehicle model (Lotus Vehicle [18]). The baseline configuration with the 4 liters engine requires $0.439 \mathrm{~kg}$ of fuel to cover the $4.052 \mathrm{~km}$ of the urban sector, and $0.850 \mathrm{~kg}$ of fuel to cover the full cycle. Considering a density of $0.75 \mathrm{~kg} /$ liter, this corresponds to a fuel economy of 14.4 litres $/ 100 \mathrm{~km}$ over the urban sector, and 10.3 litres $/ 100 \mathrm{~km}$ over the full cycle. The large naturally aspirated engine works the most part of the driving cycle at low speed and BMEP, more often around $1500 \mathrm{rpm}$ and $1 \mathrm{bar}$. The large amount of energy used to accelerate the vehicle is then lost decelerating the vehicle. The operation of the engine at idle or very low speed and BMEP is very inefficient.

Considerable improvements for this vehicle may be obtained recovering the braking kinetic energy with a KERS and stopping the engine during large portions of the cycle when the KERS provides the energy needed. Very preliminary computations have been performed assuming reference values [5-16] for maximum energy storage in KERS, energy penalties for start/stop, efficiency of storage and recovery of energy, energy requested to run ancillary loads, new ancillary loads introduced by KERS and engine warm-up profile. 


\begin{tabular}{||c|c|}
\hline Number of Cylinders & 6 \\
\hline Bore [mm] & 92.2 \\
\hline Stroke [mm] & 99.3 \\
\hline Compression ratio & 10.5 \\
\hline Swept Volume [1] & 4 \\
\hline
\end{tabular}

Table 2 - Basic engine data, full size passenger car.

\begin{tabular}{||c|c|}
\hline Weight $[\mathrm{kg}]$ & 1810 \\
\hline Frontal Area $\left[\mathrm{m}^{2}\right]$ & 2.250 \\
\hline Drag Coefficient & 0.298 \\
\hline Tyre Rolling Radius [m] & 0.316 \\
\hline Final Drive Ratio & 2.73 \\
\hline Gearbox & Automatic \\
\hline Number of ratios & 5 \\
\hline Gear. 1 Ratio & 3.22 \\
\hline Gear. 2 Ratio & 2.29 \\
\hline Gear. 3 Ratio & 1.55 \\
\hline Gear. 4 Ratio & 1 \\
\hline Gear. 5 Ratio & 0.75 \\
\hline
\end{tabular}

Table 3 - Basic vehicle data, full size passenger car.

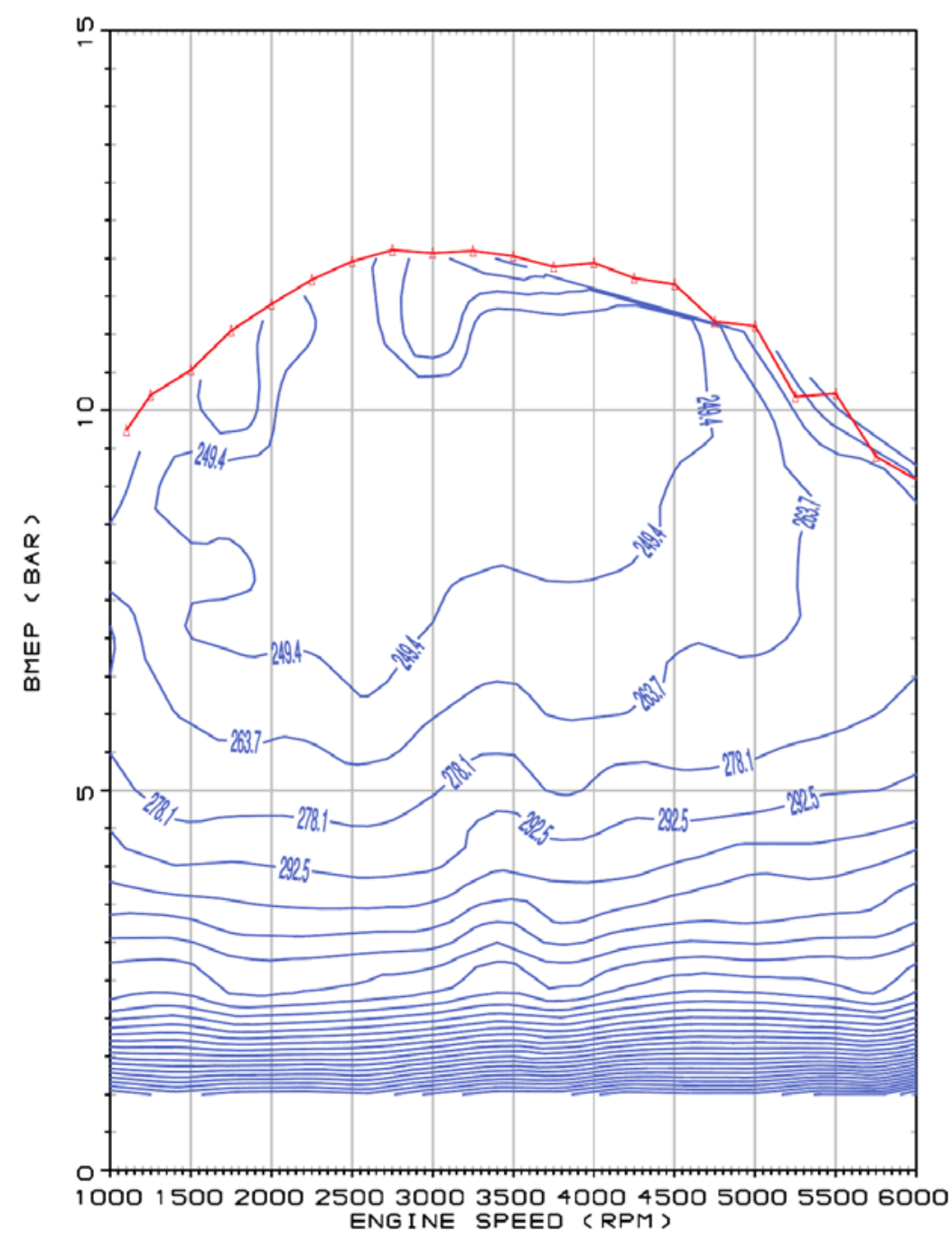

Figure 3 - Brake specific fuel consumption (in $\mathrm{g} / \mathrm{kWh}$ ) map for a 4 liters gasoline engine. 
The engine is shut down during a deceleration of the vehicle to stop. It is restarted during the following acceleration when the kinetic energy recovered during the braking is fully consumed to re-accelerate the vehicle, run the ancillaries with engine shut-down, and restart the engine. The efficiency of the charging and discharging process is supposed to be 70\% following [9-15], even if preliminary measurements made on the standalone KERS+CVT show sometimes efficiencies in excess of $70 \%$. Differences in the warm-up profile of the engine (engine metal, coolant and oil temperatures vs. time) with and without KERS are neglected.

The configuration with the 4 liters engine and KERS requires $0.27 \mathrm{~kg}$ of fuel to cover the $4.052 \mathrm{~km}$ of the urban sector, and $0.64 \mathrm{~kg}$ of fuel to cover the full cycle. This corresponds to a fuel economy of 8.8 litres/100 km over the urban sector (fuel saving of more than $35 \%$ ), and 7.7 litres/100 km over the full cycle (fuel saving of 25\%). The engine may be stopped 50\% of the time with KERS. Part of the energy recovered is lost in the start-stop of the engine.

It has to be pointed out that the vehicle stops from high speed at the end of the NEDC with immediate engine turn off. This finish wastes all the energy stored in the KERS following the sharp deceleration. Clearly the end of the NEDC cycle is very far from the real life operation of the car, and therefore real life benefits of KERS may be guessed to more than 30\% better fuel economy.

Further improvements may follow downsizing of the internal combustion engine thanks to the boosting provided by KERS during accelerations. The thermal engine in a conventional car or truck is a compromise having to provide sufficient power during full load strong accelerations, then part load high fuel conversion efficiency when the vehicle is cruising. The displacement needed to deliver sharp full load accelerations produces very poor conversion efficiencies cruising with low part load. Availability of mechanical energy in the KERS to boost accelerations may permit downsizing of the thermal engine therefore further improving the fuel economy.

The displacement effect shifts the operating BMEP up by a factor equal to the displacement ratio. In hypothesis the brake specific fuel consumption map is the same for both the original and the downsized engine. Reduction of the displacement of the engine from 4 to 3.3 liters produces an improved fuel economy of about $10 \%$ (brake specific fuel consumptions $10 \%$ better on average). This is due to the very low part load efficiencies at very low BMEP of the throttle-controlled stoichiometric large gasoline engine. The configuration with the 3.3 liters downsized engine and the KERS reduces the fuel usage to 7 liters per $100 \mathrm{~km}$ (fuel saving of $33 \%$ ).

\section{COMPACT SIZE DIESEL PASSENGER CAR}

KERS have been coupled so far to gasoline powered engines in large sedans to provide improvements of fuel economy of 20 - $25 \%$ [31]. Smaller improvements in fuel consumption but better then hybrids fuel economies may be obtained by coupling KERS to small, turbocharged Diesel engine.

Simulations have then been performed for a compact passenger car. The car is powered by a 1.6 Turbo Direct Injection (TDI) Diesel engine. Basic data of the engine and the vehicle are presented in Tables 4 and 5. Figure 4 presents the Brake Specific Fuel Consumption (BSFC) vs. Brake Mean Effective Pressure (BMEP) and engine speed. These values are computed with a validated engine model (WAVE, [17]). Results of vehicle fuel economy over the NEDC have then been obtained with a validated vehicle model (Lotus Vehicle, [18]).

The baseline configuration with the $1.6 \mathrm{TDI}$ engine requires $0.16 \mathrm{~kg}$ of fuel to cover the $4.052 \mathrm{~km}$ of the urban sector, and $0.35 \mathrm{~kg}$ of fuel to cover the full cycle. Considering a density of $0.84 \mathrm{~kg} / \mathrm{liter}$, this corresponds to a fuel economy of 4.7 litres/100 km over the urban sector, and 3.8 litres $/ 100 \mathrm{~km}$ over the full cycle. The small turbocharged engine works the most part of the driving cycle at medium speed and high BMEP. The larger efficiencies of the Diesel both top and part load resulting from the higher compression ratio, the turbo charging, the lean operation and the non throttled load control by quantity of fuel injected permits operation with much larger fuel efficiencies. However, a still significant amount of energy used to accelerate the vehicle is then lost decelerating the vehicle.

Preliminary computations have then been performed modeling a modified version with KERS of the vehicle. Reference values are again assumed for maximum energy storage in KERS, energy penalties for start/stop, efficiency of storage and recovery of energy, energy requested to run ancillary loads, new ancillary loads introduced by KERS and engine warm-up profile. The engine is shut-off during decelerations, and it is restarted during the following acceleration when the kinetic energy recovered during the braking is fully consumed.

The configuration with the 1.6TDI engine and KERS requires $0.12 \mathrm{~kg}$ of fuel to cover the $4.052 \mathrm{~km}$ of the urban sector, and $0.29 \mathrm{~kg}$ of fuel to cover the full cycle. This corresponds to a fuel economy of 3.5 litres/100 km over the urban sector (fuel saving of $25 \%$ ), and 3.16 litres $/ 100 \mathrm{~km}$ over the full cycle (fuel saving of 16\%). The engine may be stopped near 50\% of the time with KERS. Part of the energy recovered is lost in the start-stop of the engine.

Further improvements may follow downsizing of the internal combustion engine thanks to the boosting provided by KERS during accelerations. The displacement effect shifts the operating BMEP up by a factor equal to the displacement ratio. In hypothesis the brake specific fuel consumption map is the same for both the original and the downsized engine, reduction of the displacement of the engine from 1.6 to 1.2 liters produce an improved fuel economy of about $4 \%$ (brake specific fuel consumptions $4 \%$ better on average). This is due to the smaller improvements in efficiency changing the load throttle less by quantity of fuel injected as typical of Diesel. 


\begin{tabular}{|c|c|}
\hline \hline Number of Cylinders & 4 \\
\hline Bore [mm] & 79.50 \\
\hline Stroke [mm] & 80.50 \\
\hline Compression ratio & 16.5 \\
\hline Swept Volume [1] & 1.5984 \\
\hline
\end{tabular}

Table 4 - Basic engine data.

\begin{tabular}{||c|c|}
\hline Weight $[\mathrm{kg}]$ & 1336 \\
\hline Frontal Area $\left[\mathrm{m}^{2}\right]$ & 2.2 \\
\hline Drag Coefficient & 0.298 \\
\hline Tyre Rolling Radius $[\mathrm{m}]$ & 0.3080 \\
\hline Final Drive Ratio & 3.389 \\
\hline Gearbox & Manual \\
\hline Number of ratios & 5 \\
\hline Gear. 1 Ratio & 3.7780 \\
\hline Gear. 2 Ratio & 1.9440 \\
\hline Gear. 3 Ratio & 1.1850 \\
\hline Gear. 4 Ratio & 0.8160 \\
\hline Gear. 5 Ratio & 0.6250 \\
\hline
\end{tabular}

Table 5 - Basic vehicle data.

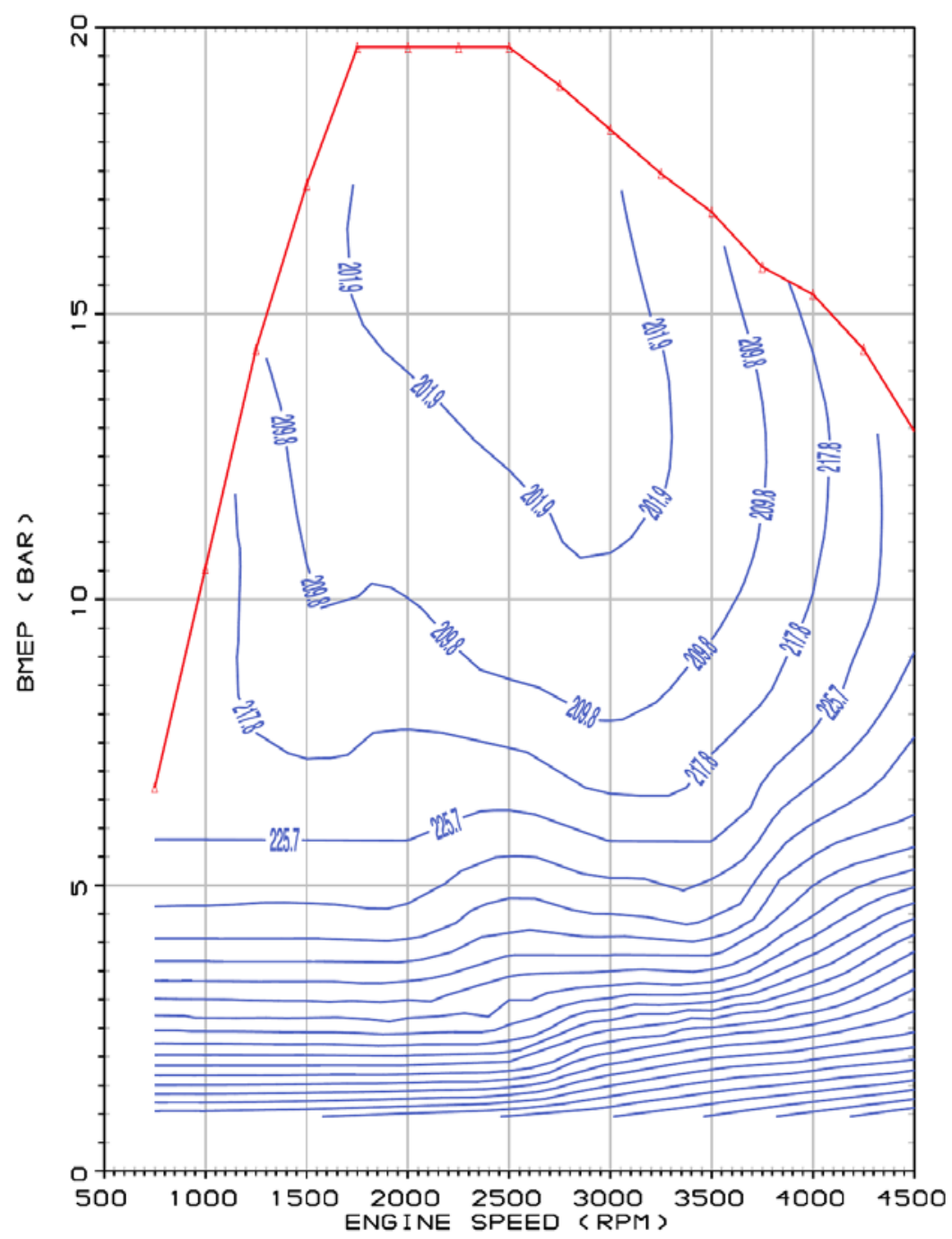

Figure 4 - Brake specific fuel consumption (in $\mathrm{g} / \mathrm{kWh}$ ) map for the 1.6 TDI Diesel engine. 
The configuration with the downsized 1.2TDI engine and the KERS reduces the fuel usage to 3.04 liters per $100 \mathrm{~km}$, with a fuel saving of $21 \%$.

The configuration with the 1.6TDI Diesel engine and KERS reduces the production of $\mathrm{CO}_{2}$ to $82.4 \mathrm{~g}$ per km. These $\mathrm{NEDC} \mathrm{CO}_{2}$ values are $7 \%$ better than those of today's best same size hybrid electric vehicle, rated at $89 \mathrm{~g}$ of $\mathrm{CO}_{2}$ per $\mathrm{km}$ [32]. Downsizing the engine to 1.2 liters, production of $\mathrm{CO}_{2}$ reduces to $79.2 \mathrm{~g}$ of $\mathrm{CO}_{2}$ per $\mathrm{km}$. These $\mathrm{CO}_{2}$ values are $11 \%$ better than those of today's best same size hybrid electric vehicle.

Clearly, the end of the NEDC cycle with the stop of the vehicle from high speed and immediate engine turn off is very far from the real life operation of the car. Real life benefits of KERS may therefore be guessed to be even more fuel saving.

\section{HEAVY DUTY VEHICLE CYCLES}

Current regulations do not require complete heavy-duty diesel and gas vehicles to be chassis certified, instead requiring certification of their engines [19-22]. Many driving cycles have been proposed to represent real world driving for emissions and fuel consumption testing [23-28]. However, these cycles are not part of current emission regulations and their validity is not globally recognized.

The World-Wide Harmonized Heavy-Duty Certification (WHDC) Procedure applies to Diesel and gas engines (natural gas or LPG) [19-22] tested on engine dynamometers. WHDC is based on the world-wide pattern of real non hybrid heavy commercial vehicle use. From the collected data, two representative test cycles, a transient test cycle (WHTC) with both cold and hot start requirements and a hot start steady state test cycle (WHSC), have been created covering typical driving conditions in the European Union (EU), the United States of America, Japan and Australia. The WHTC and WHSC test procedures reflect world-wide on-road heavy-duty engine operation on vehicles with non-hybrid power trains. Therefore, the benefits KERS may introduce in heavy duty vehicles have to be evaluated on cycles having a limited recognition.

Different drive cycles may be considered following the application, highway line haul, regional haul, local pick up and delivery, neighbourhoods refuse truck, utility service truck, transit bus, intermodal drayage truck. Other options to be considered my include drive cycle load requirements as accessory load, cargo load and power take-off (PTO) and service load. All these cycles have the problem of being really representative of a given application versus broad diversity of actual in-use fleet operations. Large fleets distrust short tests, and more actual duty cycle data is needed to further develop these cycles. Finally, complex cycles will have a lower repeatability than a series of modal tests at steady state.

The Highway Line Haul - United States Environmental Protection Agency (EPA) or the Highway Line Haul - Northeast States for Coordinated Air Use Management (NESCAUM)/ Southwest Research Institute (SwRI) cycles already offer some options to recover the braking energy therefore improving the fuel economy and reducing Green House Gases (GHG) and possibly other emissions. However, the Local Delivery -Class 4 (Neighbourhood), the Local Delivery-Class 6 (Business), the Neighbourhood Refuse Truck, the Utility Service Truck or the Intermodal Drayage Truck cycles and all of the transit bus cycles certainly offer much better opportunities to achieve better fuel economies with KERS.

\section{HEAVY DUTY DIESEL TRUCK}

In the previous application, KERS have been coupled to both gasoline powered full size and Diesel powered compact size passenger cars, with fuel economy benefits larger in the gasoline rather than in the Diesel option, but however more than $30 \%$ on the ECE sector of the NEDC. Improvements in fuel consumption may also be obtained by coupling KERS to a heavy duty truck powered by a turbocharged Diesel engine.

The truck is a front axle refuse truck powered by an 11TDI Diesel engine with an 8-Speed transmission to the rear axle of Ratios 17.77 Low to $0.71 \mathrm{High}$. Basic data of the engine and the vehicle are presented in Tables 6 and 7. Figure 5 presents the Brake Specific Fuel Consumption (BSFC) vs. Brake Mean Effective Pressure (BMEP) and engine speed. These values are computed with a validated engine model (WAVE, [17]).

Because the WHDC discussed above is an engine dynamometer test and not a chassis dynamometer test, first simulations have been performed with a vehicle model (Lotus Vehicle, [18]) over a version of the hot ECE+EUDC cycle modified for top velocity $80 \mathrm{~km} / \mathrm{h}$ as more reasonable for a heavy duty truck of almost $11,000 \mathrm{~kg}$ weight. The special hot ECE+EUDC velocity scheduled is shown in Figure 6.

\begin{tabular}{||c|c||}
\hline Number of Cylinders & 6 \\
\hline Bore [mm] & 123 \\
\hline Stroke [mm] & 152 \\
\hline Compression ratio & 16 \\
\hline Swept Volume [1] & 11 \\
\hline
\end{tabular}

Table 6 - Basic engine data. 


\begin{tabular}{||c|c|}
\hline Weight [kg] & 10,950 \\
\hline Frontal Area [m $]$ & 4.75 \\
\hline Drag Coefficient & 0.74 \\
\hline Tyre Rolling Radius [m] & 0.54 \\
\hline Final Drive Ratio & 5 \\
\hline Gearbox & Manual \\
\hline Number of ratios & 8 \\
\hline Gear. 1 Ratio & 17.7 \\
\hline Gear. 2 Ratio & 10.94 \\
\hline Gear. 3 Ratio & 6.57 \\
\hline Gear. 4 Ratio & 4.05 \\
\hline Gear. 5 Ratio & 2.54 \\
\hline Gear. 6 Ratio & 1.57 \\
\hline Gear. 7 Ratio & 1 \\
\hline Gear. 8 Ratio & 0.71 \\
\hline & \\
\hline
\end{tabular}

Table 7 - Basic vehicle data.

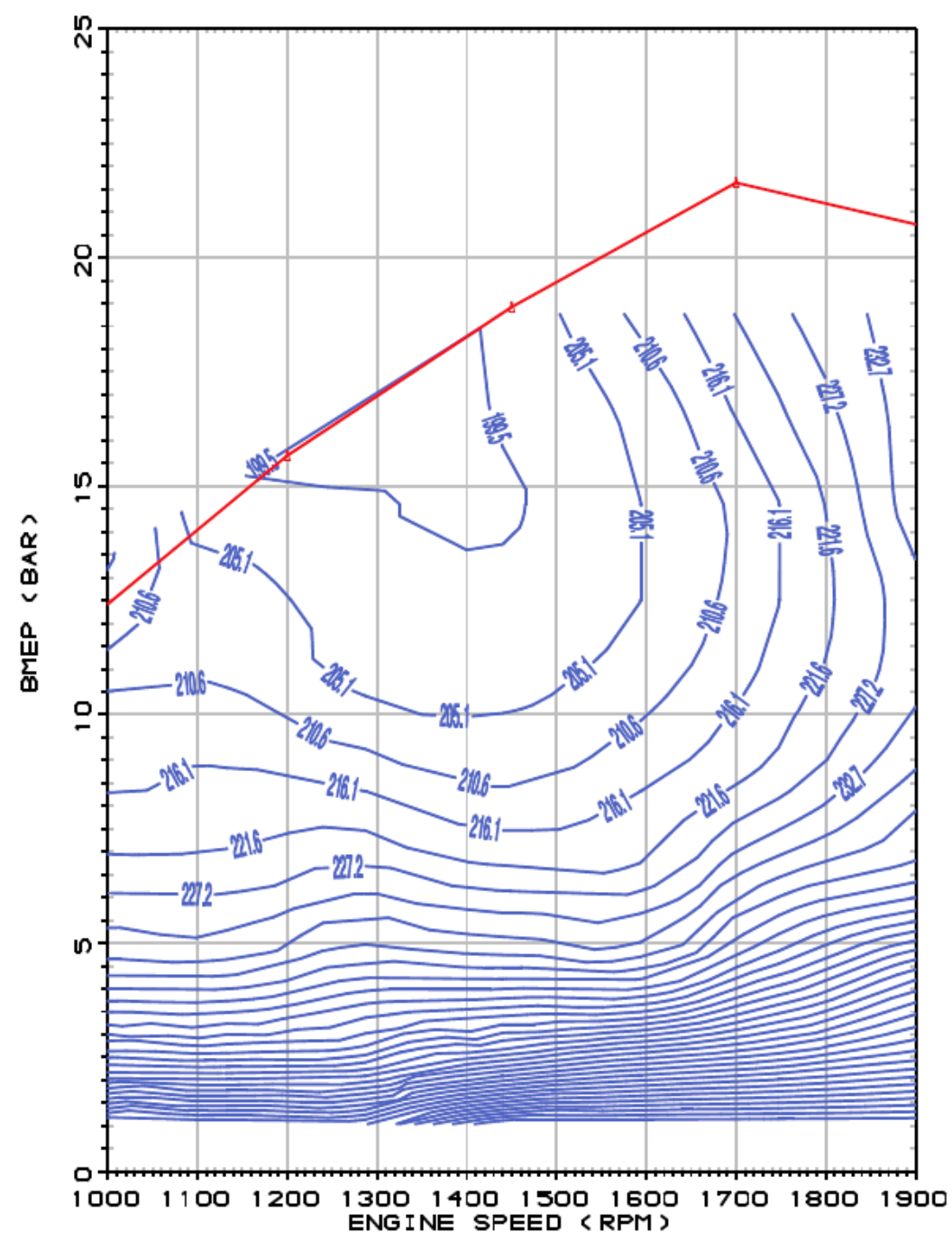

Figure 5 - Brake specific fuel consumption (in $\mathrm{g} / \mathrm{kWh}$ ) map for the 11TDI Diesel engine. 


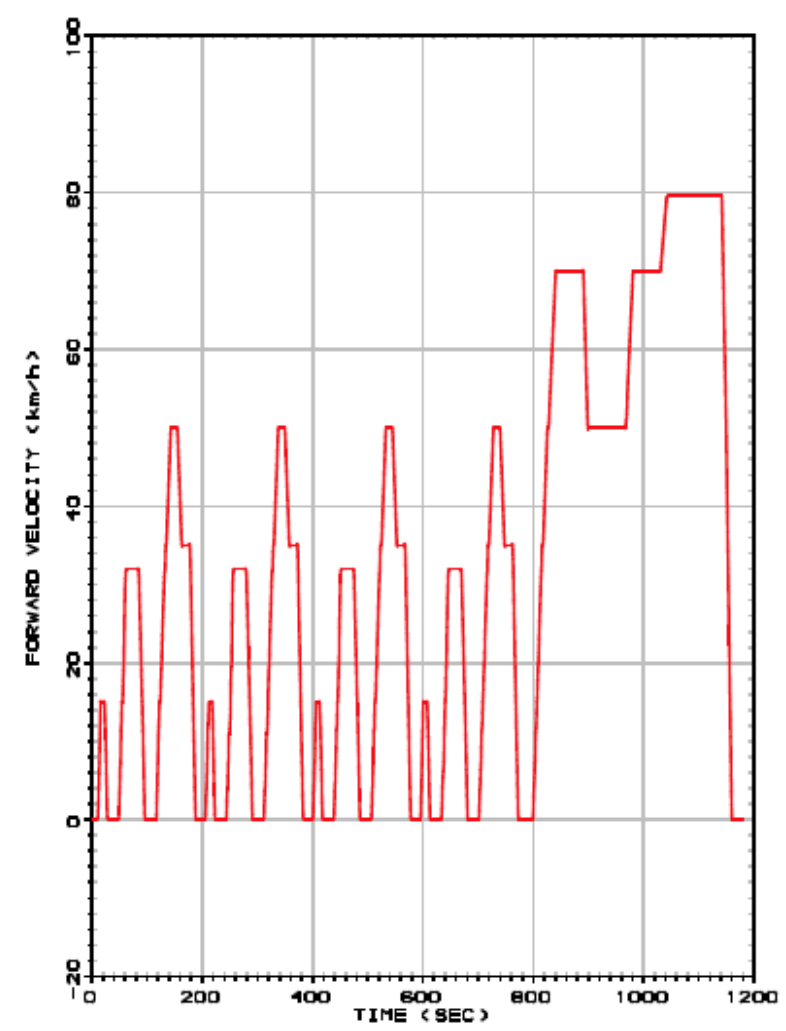

Figure 6 - Modified ECE+EUDC velocity schedule for fuel consumption of heavy duty trucks.

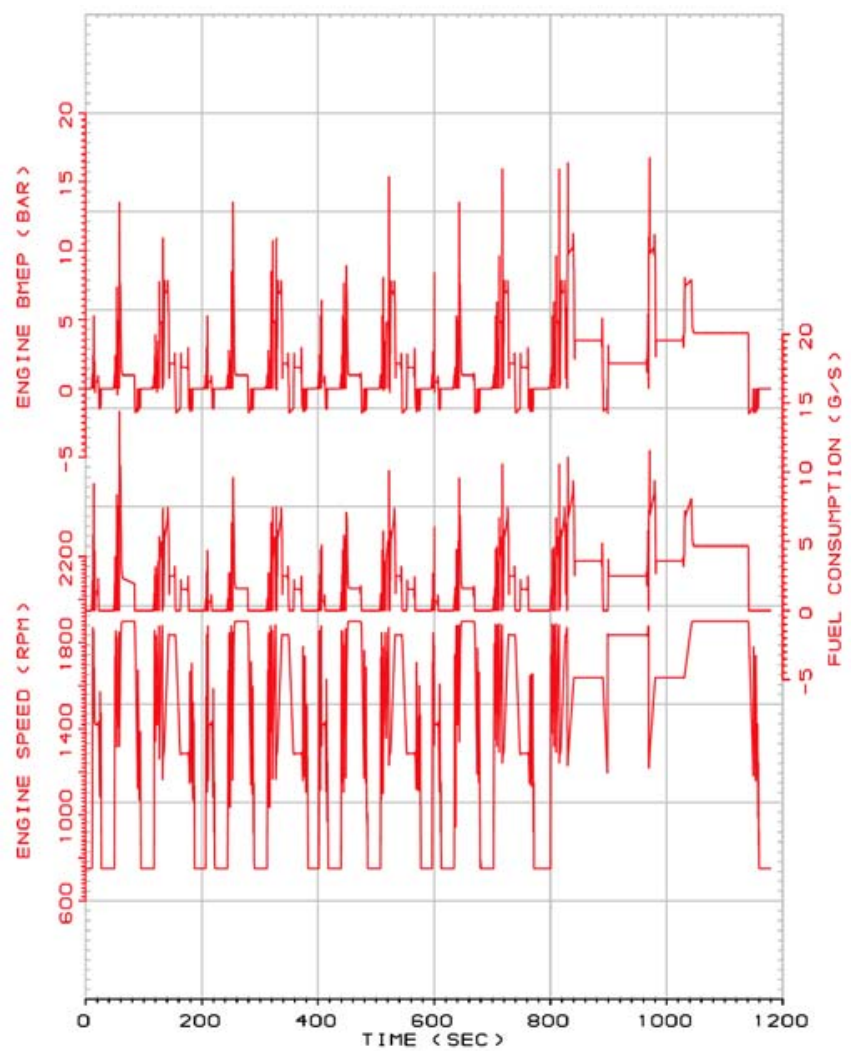

Figure 7 - Hot modified ECE+EUDC results (standard configuration without KERS).

Figure 7 presents the computed brake mean effective pressure, speed and fuel consumption over the hot ECE+EUDC cycle for the standard driveline without KERS. The baseline configuration with the 11 TDI engine requires $2.85 \mathrm{~kg}$ of fuel to cover the full cycle. 
Considering a density of $0.84 \mathrm{~kg} /$ liter, this corresponds to a fuel economy of 31.1 litres $/ 100 \mathrm{~km}$ over the full cycle or $7.55 \mathrm{Miles}$ per US Gallon.

The larger efficiencies of the Diesel both top and part load resulting from the higher compression ratio, the turbo charging, the lean operation and the non throttled load control by quantity of fuel injected permits operation with large fuel efficiencies. However, a still significant amount of energy used to accelerate the vehicle is then lost decelerating the vehicle. The shift schedule is set to use the engine in between 1,200 rpm and 1,900 rpm operating points. The configuration with the $11 \mathrm{TDI}$ engine and KERS requires $2.15 \mathrm{~kg}$ of fuel to cover the full cycle. This corresponds to a fuel economy of 23.8 litres/100 km over the full cycle with a fuel saving of $25 \%$.

\section{CONCLUSIONS}

KERS based on a high speed flywheel and a constant variable transmission concept should provide efficient regenerative braking and torque assistance as a means of dramatically improving efficiency and hence reducing fuel consumption and $\mathrm{CO}_{2}$ emissions.

Computational models have been developed to compute the brake specific fuel consumption maps of: a Gasoline engine powered full size passenger car, a Diesel engine powered compact passenger car and a Diesel engine powered heavy duty truck. Table 8 summarizes the computed fuel economy benefits of KERS.

\begin{tabular}{|c|c|c|c|}
\hline Vehicle & Full size passenger car & Compact size passenger car & Heavy Duty Truck \\
\hline Cycle & NEDC & NEDC & Hot ECE+EUDC Low Speed \\
\hline Fuel & gasoline & Diesel & Diesel \\
\hline Engine Displacement [1] & 4 & 1.6 & 11 \\
\hline Weight $[\mathrm{kg}]$ & 1,810 & 1,336 & 10,950 \\
\hline \multicolumn{4}{|c|}{ Standard driveline } \\
\hline Fuel consumption $[1 / 100 \mathrm{~km}]$ & 10.3 & 3.8 & 31.1 \\
\hline \multicolumn{4}{|c|}{ Driveline with KERS } \\
\hline Fuel consumption [1/100 km] & 7.7 & 3.2 & 23.8 \\
\hline Improvement in fuel economy & $25 \%$ & $16 \%$ & $23 \%$ \\
\hline \multicolumn{4}{|c|}{ Driveline with KERS and downsizing of engine } \\
\hline Engine Displacement [1] & 3.3 & 1.2 & \\
\hline Fuel consumption $[1 / 100 \mathrm{~km}]$ & 7 & 3 & \\
\hline Improvement in fuel economy & $32 \%$ & $21 \%$ & \\
\hline
\end{tabular}

Table 8 - Improvements of fuel economies in passenger car and heavy duty truck applications.

Passenger cars powered by large naturally aspirated gasoline engines are those that benefit more by using a KERS. With KERS fuel economy improves more than $25 \%$ over the NEDC. Significant improvements of $16 \%$ are obtained in passenger cars powered by Diesel engines. Diesel powered heavy duty trucks operating full load during acceleration provide improvements of $23 \%$.

Heavy transportation has a large fuel cost of and large production of carbon dioxide. The technique may deliver large improvements in fuel economy with consequently reduced operational costs as well as a much smaller carbon dioxide footprint.

The benefits of flywheel based KERS are similar to hydraulic regenerative braking but with the advantage of reduced complexity, less space needed and simpler construction and operation.

The cost as well as the packaging and weight of a KERS for truck are not an issue as in passenger car applications. Two counter rotating flywheels could possibly solve the stability issue due to the increased rotating mass required for braking vehicles of considerable weight.

The energy boost by KERS may be beneficial more to help trucks climbing hills rather than for engine downsizing, also providing a better road safety. KERS will also collect considerable energy braking down hills reducing the need for engine brakes and thus noise.

The Author has been involved in the past in other R\&D activities having had in the beginning less brilliant perspectives than KERS, namely the revolutionary FIAT Uni-jet Diesel common rail direct injection system that changed the passenger car market in Europe during the 90s, or the FIAT Multi-Air pneumatic valve actuation system that is now the first fully variable hydraulic valve actuation system in production. It is the Author opinions that it is more the current financial melt down than the challenges or limitations for KERS which prevent it to be realized currently.

\section{REFERENCES}

1. Australian Government Bureau of Infrastructure, Transport and Regional Economics, "Information sheet 34 - Road and rail freight: competitors or complements", DOTARS ID 08470, ISSN 1836-697X, July 2009. http://www.bitre.gov.au/publications/23/Files/IS34_RoadRailFreight.pdf 
2. Australian Government Department of Climate Change, "Australia's National Greenhouse Gas Inventory: Update Quarterly Estimates of Australia's National Inventory: March Quarter 2009”

http://www.climatechange.gov.au/inventory/2007/pubs/quarterly-updatenggi.pdf

3. US Department of energy, Energy efficiency and renewable energy, vehicle technology program, "FY 2008 Progress report For Advanced combustion engine technologies".

http://www1.eere.energy.gov/vehiclesandfuels/pdfs/program/2008_adv_combustion_engine.pdf

4. Kepner, R. P., "Hydraulic Power Assist - A Demonstration of Hydraulic Hybrid Vehicle Regenerative Braking in a Road Vehicle Application”, SAE P. 002-01-3128.

5. http://www.flybridsystems.com/Technology.html (retrieved January 8, 2010).

6. http://www.torotrak.com/IVT/works/ (retrieved January 8, 2010).

7. http://www.xtrac.com/pdfs/Torotrak_Xtrac_CVT.pdf (retrieved January 8, 2010).

8. http://www.bhr-technology.com/CPC-KERS.pps (retrieved January 8, 2010).

9. Stone, R., "Full-toroidal variable drive transmission systems in mechanical hybrid systems - from Formula 1 to road cars", CTI Symposium and Exhibition: Automotive Transmissions, Berlin, Germany, December 2009.

http://www.torotrak.com/Resources/Torotrak/Documents/Mech\%20hybrid\%20paper_CTI\%20Berlin09.pdf (retrieved January 11, 2010).

10. Body, W. and Brockbank, C., "Simulation of the fuel consumption benefits of various transmission arrangements and control strategies within a flywheel based mechanical hybrid system", VDI Transmissions in Vehicles Conference and Exhibition, Friedrichshafen, June 2009.

http:/www.torotrak.com/Resources/Torotrak/Documents/VDI\%20Friedrichshafen\%202009.pdf (retrieved January 11, 2010).

11. Brockbank, C., and Greenwood, C., "Full-toroidal variable drive transmission systems in mechanical hybrid systems - from Formula 1 to road vehicles", CTI Symposium and Exhibition: Automotive Transmissions, Detroit, May 2009.

http://www.torotrak.com/Resources/Torotrak/Documents/CTI\%20Detroit\%20Paper\%202009.pdf (retrieved January 11, 2010).

12. Brockbank, C., "Application of a variable drive to supercharger and turbo compunder applications”, SAE World Congress, Detroit, April 2009. 09PFL-0925

http://www.torotrak.com/Resources/Torotrak/Documents/SAE_WC 2009 09PFL-0925_Variable_Drive_Boost_System.pdf (retrieved January 11, 2010).

13. Brockbank, C., and Cross, D., "Mechanical hybrid system comprising a flywheel and CVT for motorsport and mainstream automotive applications", SAE World Congress, Detroit, April 2009. 09PFL-0922.

http://www.torotrak.com/Resources/Torotrak/Documents/SAE_WC_2009_09PFL-0922_KERS.pdf (retrieved January 11, 2010).

14. Brockbank, C. and Greenwood, C. , "Full-toroidal variable drive transmssion systems in mechanical hybrids - from Formula 1 to road vehicles", CTI Innovative Automotive Transmissions Conference and Exhibition, Berlin, December 2008.

http://www.torotrak.com/Resources/Torotrak/CTI Berlin 2008.pdf (retrieved January 11, 2010).

15. Brockbank, C. and Greenwood, C. "Formula 1 mechanical hybrid applied to mainstream automotive", VDI Getriebe in Fahrzeuge Conference, June 2008.

http://www.torotrak.com/Resources/Torotrak/VDI_2008.pdf (retrieved January 11, 2010).

16. http://www.ricardo.com/Documents/PRs\%20pdf/PRs\%202009/Ricardo\%20Kinergy\%20delivers\%20breakthrough\%20technolog $\mathrm{y} \% 2010 \mathrm{w} \% 20 \operatorname{cost} \% 20$ hybridisation.pdf (retrieved January 12, 2010).

17. http://www.ricardo.com/engb/Software/Productoffering--description/WAVE1/ (retrieved January 8, 2010).

18. http://www.lesoft.co.uk/index1.html (retrieved January 8, 2010).

19. www.unece.org/trans/doc/2003/wp29grpe/TRANS-WP29-GRPE-46-inf04e.pdf (retrieved April 1, 2010).

20. www.unece.org/trans/doc/2001/wp29grpe/TRANS-WP29-GRPE-41-inf01.pdf (retrieved April 1, 2010).

21. www.dieselnet.com/standards/cycles/whtc.php (retrieved April 1, 2010).

22. www.dieselnet.com/standards/cycles/whsc.php (retrieved April 1, 2010).

23. Matthew Barth, Theodore Younglove, George Scora, "Development of a Heavy-Duty Diesel Modal Emissions and Fuel Consumption Model", California PATH Research Report UCB-ITS-PRR-2005-1.

www.path.berkeley.edu/PATH/Publications/PDF/PRR/2005/PRR-2005-01.pdf (retrieved April 1, 2010).

24. NilsOlof Nylund, Kimmo Erkkilä, Nigel Clark and Greg Rideout, "Evaluation of duty cycles for heavy duty urban vehicles", Final report of IEA AMF Annex XXIX.

www.vtt.fi/inf/pdf/tiedotteet/2007/T2396.pdf (retrieved April 1, 2010).

25. Coralie Cooper, Fanta Kamakaté, Thomas Reinhart, Matthew Kromer, Robert Wilson, "REDUCING Heavy-Duty Long Haul Combination Truck Fuel Consumption and CO2 Emissions". Northeast States for Coordinated Air Use Management (NESCAUM) report.

www.nescaum.org/documents/heavy-duty-truck-ghg_report_final-200910.pdf (retrieved April 1, 2010).

26. Carl Ensfield, L. Joseph Bachman, Anthony Erb, Cheryl Bynum, "Evaluating Real-World Fuel Economy on Heavy Duty Vehicles using a Portable Emissions Measurement System", SAE P. 2006-01-3543.

27. Cheryl Bynum, "Drive Cycle Development". U.S. EPA (Environmental Protection Agency) report.

www.epa.gov/smartway/documents/drive-cycle-development.pdf (retrieved April 1, 2010).

28. U.S. EPA (Environmental Protection Agency), "SmartWay Fuel Efficiency Test Protocol for Medium and Heavy Duty Vehicles". www.epa.gov/smartway/documents/420p07003.pdf (retrieved April 1, 2010). 
28. van Druten, R. M., "Transmission Design of The Zero Inertia Powertrain". PhD Thesis, Technische Universiteit Eindhoven, Netherlands, 2001.

alexandria.tue.n1/extra2/200141350.pdf (retrieved July 5, 2010).

29. http://www.dieselnet.com/standards/cycles/ece_eudc.html (retrieved July 5, 2010).

30. Boretti, A. A., "Improvements of vehicle fuel economy using mechanical regenerative braking", paper accepted 3-7-2010 for publication in the International Journal of Vehicle Design.

31. http://www.vcacarfueldata.org.uk/ (retrieved June 22, 2010).

32. Brockbank, C., and Greenwood, C., "Development of the Epicycloidal Roller Control System for the Torotrak Full-Toroidal Infinitely Variable Transmission ", SAE P. 2009-01-1540.

33. Brockbank, C., and Greenwood, C., "Fuel Economy Benefits of a Flywheel \& CVT Based Mechanical Hybrid for City Bus and Commercial Vehicle Applications", SAE P. 2009-01-2868.

\section{NOMENCLATURE}

BITRE Australian government Bureau of Infrastructure, Transport and Regional Economics

BMEP

BSFC

CVT

ECE

EPA

EUDC

GHG

HRB

KERS

NEDC

NESCAUM

R\&D

SwRI

TDI

Brake Mean Effective Pressure

Brake Specific Fuel Consumption

Continuously Variable Transmission

Economic Commission for Europe

United States Environmental Protection Agency

Extra Urban Driving Cycle

Green House Gases

Hydraulic Regenerative Braking

Kinetic Energy Recovery System

New European Driving Cycle

Northeast States for Coordinated Air Use Management

Research and Development

Southwest Research Institute

WHDC

WHTC

Turbo Direct Injection

World-Wide Harmonized Heavy-Duty Certification

World-Wide Harmonized Transient Cycle

WHSC

World-Wide Harmonized steady state test cycle 